Painful swelling of the calf

\section{A man with swollen calf and discoloration of the foot}

\section{Y Berkun, K Sade, Y Naparstek}

Answers on $p 304$.

A 48 year old man was admitted to the emergency department because of painful swelling of his right calf that had developed gradually during the previous week. He denied cough, dyspnoea, or chest pain. He had no history of a previous thromboembolic event, local trauma, or dehydration. Six months earlier he was diagnosed as suffering from psoriatic arthritis and treated with sulphasalazine, which was stopped after two months because of drug induced hepatitis.

On physical examination he was afebrile and without dyspnoea. His lungs were clear. The left knee was mildly swollen, with a full range of motion and no clear effusion. No palpable popliteal cyst was found. His left calf was tender, swollen, with erythematous skin (fig 1). Homan's sign was positive. Pitting oedema of the foot, maximal in the medial malleolus area, with purple discoloration, were noticed. Venous duplex scanning performed in the emergency department excluded deep vein thrombosis (DVT).

The patient was discharged and referred for further follow up in the outpatient clinic.

\section{QUESTIONS}

(1) What is the likely diagnosis?

(2) What physical examination sign was the clue for the final diagnosis?

(3) What are the diagnostic modalities you would use to confirm the diagnosis? (4) What treatment is indicated?

Postgrad Med J 2002;78:300

\section{Authors' affiliations}

Y Berkun, K Sade, Y Naparstek, Department of Medicine, Clinical Immunology and Allergy Unit, Hadassah University Hospital, Jerusalem, Israel
Correspondence to: $\operatorname{Dr} Y$ Berkun, Department of Pediatrics, Bikur Cholim General Hospital, POB 492, Jerusalem 91004, Israel; berkun@md.huji.ac.il

Submitted 11 September 2001

Accepted 26 October 2001

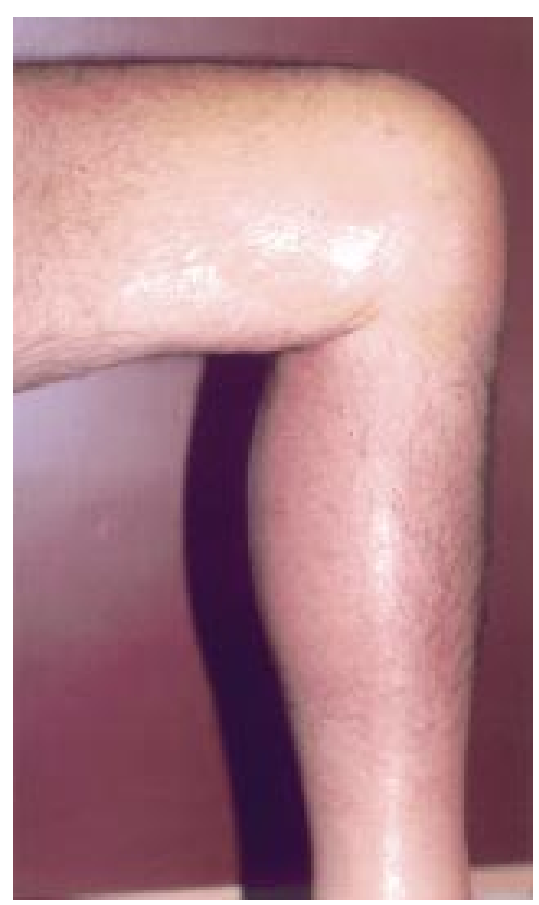

Figure 1 A lateral view showing the swollen and erythematous left calf.

\title{
Young male with pancytopenia: an unusual cause
}

\author{
R Rajput, S B Siwach, S Singh, U Singh, Meena
}

\section{Answers on p 304.}

$\Lambda^{1}$ 16 year boy, resident of Bihar, presented to the emergency department with a history of generalised weakness for one month, and bleeding from his gums for eight days. There was no history of prolonged fever, haematemesis, haematuria, or haemoptysis. The patient had not taken any drug in the recent past. On examination he had severe pallor. Examination of the cardiovascular system revealed an ejection systolic murmur in the pulmonary area. The rest of the physical examination was normal. Laboratory examination showed a haemoglobin concentration of $20 \mathrm{~g} / \mathrm{l}$ and total leucocyte count of $3.1 \times 10^{9} / 1$ with differential leucocyte count of $19 \%$ neutrophils, $78 \%$ lymphocytes, $2 \%$ monocytes, and $1 \%$ eosinophils. Platelet count was $28 \times 10^{9} /$. Anaemia was normocytic normochromic. No haemoparasites were seen on peripheral smear examination. All other investigations-biochemical (blood urea, serum creatinine, and liver function tests), chest radiography, and ultrasound of the abdomen-were normal. Bone marrow aspiration revealed cellular marrow smear; myeloid:erythroid ratio was reversed; erythropoiesis was normoblastic to mildly megaloblastic; myeloid cells showed maturation arrest; plasma cells were normal; reticulum cells were increased, and reticular iron grade was II-III with normal sideroblasts. A haemoparasite was seen in bone marrow. No abnormal cells were seen. In view of pancytopenia and relative decrease of myeloid cells and megakaryocytes in bone marrow, the possibility of toxic suppression of marrow was considered.

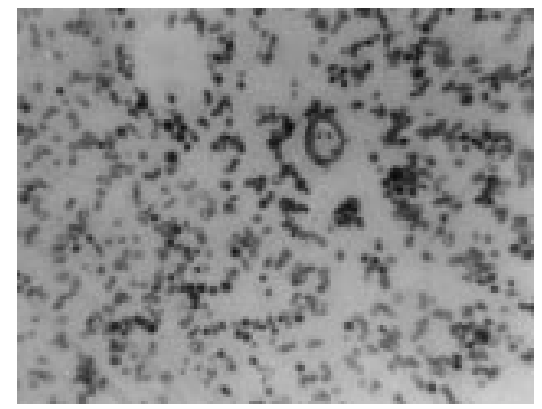

Figure 1 Bone marrow aspiration smear. 


\section{QUESTIONS}

(1) What is the finding on slide of bone marrow examination (fig 1 )?

(2) What are the causes of pancytopenia?

(3) How will you treat this patient?

Postgrad Med J 2002;78:301
Authors' affiliations

R Rajput, S B Siwach, Department of

Medicine, Pt B D Sharma Postgraduate Institute

of Medicine Sciences, Rohtak, Haryana, India

S Singh, U Singh, Department of Pathology

Meena, Department of Social and Preventive Medicine
Correspondence to: Dr Rajesh Rajput

29/9J, Medical Enclave, Pt BDS PGIMS, Rohtak 124001, Haryana, India

rajputrajmeena@rediffmail.com or

rajputrajmeena@hotmail.com

Submitted 2 July 2001

Accepted 27 November 2001

Painful elbow

\section{Recurrent painful locking of the elbow joint}

\section{R Thonse, M Belthur}

Answers on $p 305$.

\section{Authors' affiliations}

R Thonse, M Belthur, Department of

Orthopaedics, Alexandra Hospital, Redditch, UK

Correspondence to: MrR Thonse, Room 3, Flat 6, RMO Block, Hull Royal Infirmary, Hull HU3 2J2, UK;

rthonse@hotmail.com

Submitted 29 May 2001

Accepted 7 August 2001

A 45 year old, right handed bank clerk presented with pain and intermittent locking of the left elbow of 12 months' duration. Pain was intermittent and was activity related. The left elbow locked intermittently on movement, with self manoeuvres of the patient unlocking it. There was no history of trauma or history suggestive of inflammatory arthropathy.

The left elbow had a fixed flexion deformity of 30 degrees with range of motion from 30 to 120 degrees with firm block to further flexion. Rotations of the left forearm were full and pain-free. There was no joint line tenderness. The radiographs of the left elbow are shown below in figs 1 and 2 .

\section{QUESTIONS}

(1) What are the features seen on the radiographs?

(2) What is the likely diagnosis?

(3) What is the line of management?

Postgrad Med J 2002;78:301

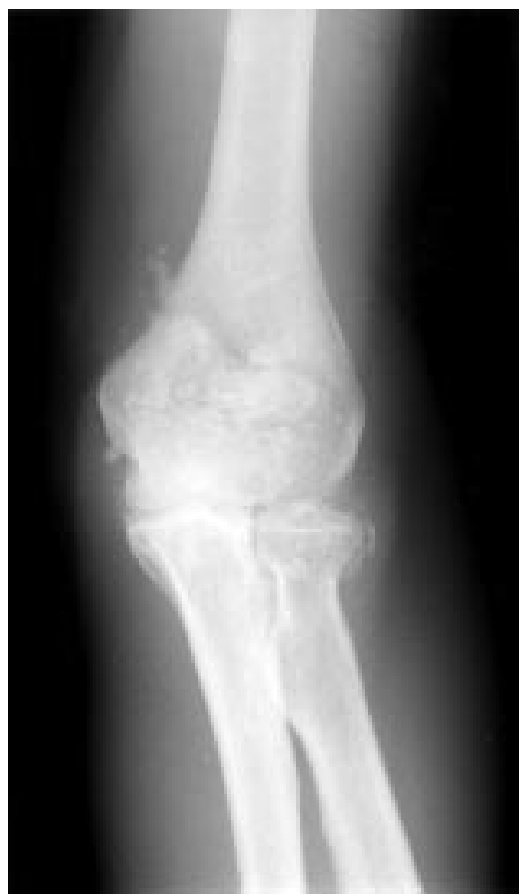

Figure 1 Anteroposterior view of left elbow joint.

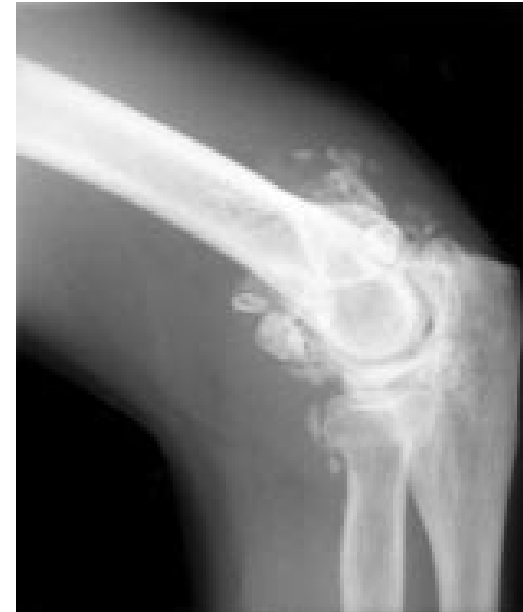

Figure 2 Lateral view of the left elbow joint. 
Verrucous lesion

\section{$A$ verrucous lesion of the palm}

\section{Vijaikumar, D M Thappa, K Karthikeyan, S Jayanthi}

Answers on $p 305$.

A 45 year old man from South India had an asymptomatic verrucous plaque on the right palm with multiple haemorrhagic spots on the

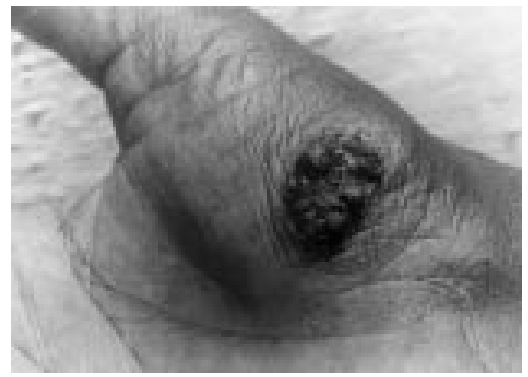

Figure 1 Single verrucous lesion of the palm. surface (fig 1) for the past three years. He also had a verrucous nodule on his left elbow. He gave a history of a reddish mass

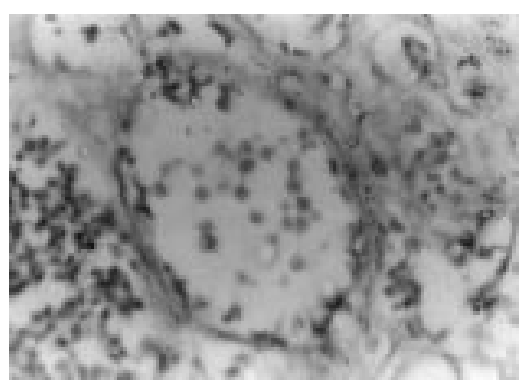

Figure 2 Photomicrograph showing thick walled sporangia containing spores in the epidermis (haematoxylin and eosin $\times 200$ ).

Pulmonary disease

\section{An unusual case of clinicoradiological dissociation}

\section{Mahendran, N B S Mani, S Jogai, A N Aggarwal}

Answers on $p 306$.

A 28 year old truck driver was seen at this institute with an abnormal chest radiograph (fig 1). He

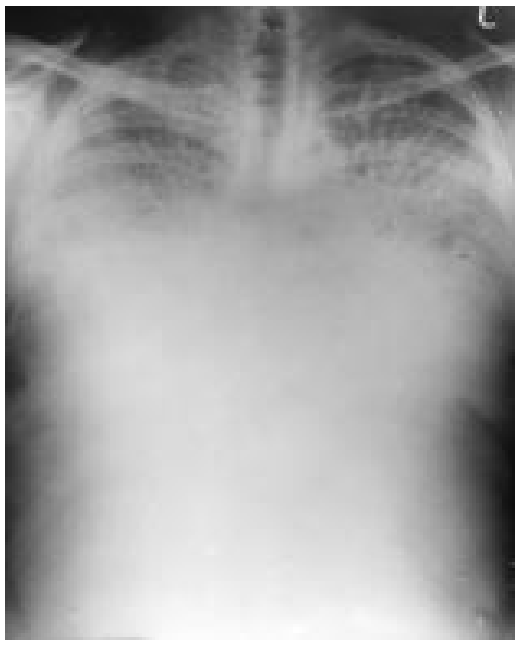

Figure 1 Chest radiograph of the patient. complained of non-specific chest pain for the past three years, and denied any other respiratory symptom. He had no significant occupational exposure to organic or mineral dust. His clinical examination was essentially normal. He had a respiratory rate of 20 breaths/min. Spirometry showed mild restrictive abnormality with vital capacity (VC) of

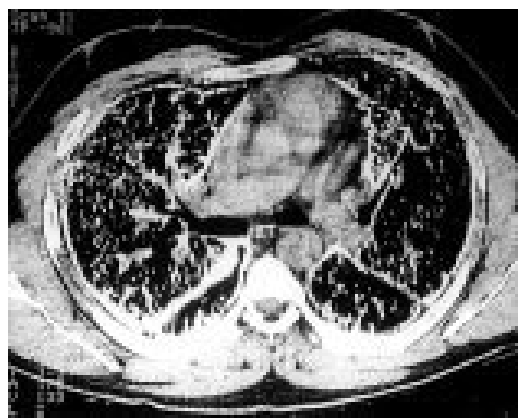

Figure 2 Computed tomogram of the chest. in both nostrils, which had recurred three times after excision in the past 15 years. At present he did not have any nasal lesions, but on examination of the oral cavity, a reddish polyp was observed hanging from the posterior surface of soft palate. Histopathological examination of the skin lesion was diagnostic (fig 2).

\section{QUESTIONS}

(1) What is your diagnosis?

(2) How can you confirm your diagnosis?

(3) What is the treatment of this disease?

Postgrad Med J 2002;78:302

\section{Authors' affiliations}

M Vijaikumar, D M Thappa, K Karthikeyan,

Department of Dermatology and Sexually

Transmitted Diseases, Jawaharlal Institute of

Postgraduate Medical Education and Research

(JIPMER), Pondicherry 605006, India

S Jayanthi, Department of Pathology

Correspondence to: Dr Thappa;

dmthappa@satyam.net.in or

dmthappa@jipmer.edu

Submitted 30 October 2001

Accepted 19 December 2001

$2.72 \mathrm{l}(64.45 \%$ of predicted $)$; forced expiratory volume in first second $\left(\mathrm{FEV}_{1}\right)$ of 2.51 ( $71.02 \%$ of predicted) and $\mathrm{FEV}_{1} / \mathrm{VC}$ ratio of $91.9 \%$. Arterial blood gas analysis on room air showed normoxaemia with an arterial oxygen pressure of $12.3 \mathrm{kPa}$ (92 $\mathrm{mm} \mathrm{Hg}$ ) with an oxygen saturation of $97 \%$. Blood counts and biochemical tests for renal and hepatic functions were normal. Computed tomography of his chest is shown in fig 2 .

\section{QUESTIONS}

(1) What are the findings on the chest radiograph and computed tomogram of the chest?

(2) What is the likely diagnosis?

(3) What additional investigations should be performed to confirm the diagnosis?

(4) What is the treatment and prognosis of the condition?

Postgrad Med J 2002;78:302

\section{Authors' affiliations}

C Mahendran, A N Aggarwal, Department of Pulmonary Medicine, Postgraduate Institute of Medical Education and Research, Chandigarh 160012, India

N B S Mani, Department of Radiodiagnosis

S Jogai, Department of Histopathology

Correspondence to: Dr Aggarwal; anaggarwal@yahoo.com

Submitted 3 December 2001

Accepted 4 January 2002 
Anaemia

\section{Anaemia: an unusual cause}

\section{A Shenoy, M P N Lewis, P Preston}

A previously fit 27 year old man presented to the gastroenterologists with a three month history of tiredness. There was no history of haematemesis, but he did complain of the passage of black stools on rare occasions. On examination temperature, pulse, and blood pressure were normal. There was no lymphadenopathy. Chest and abdominal examination were normal.

Laboratory investigations revealed a picture of iron deficiency with a haemoglobin concentration of $92 \mathrm{~g} / \mathrm{l}$, mean corpuscular volume $70.5 \mathrm{fl}$, mean corpuscular haemoglobin $21.8 \mathrm{pg}$, platelets $262 \times$ $10^{9} / 1$, and an erythrocyte sedimentation rate of $13 \mathrm{~mm} /$ hour.

Upper gastrointestinal endoscopy revealed mild gastritis. He was negative for Helicobacter pylori and distal duodenal biopsies were normal. Chest radiography and colonoscopy were normal. He then underwent a barium follow through (see fig 1).

\section{QUESTIONS}

(1) Describe the features on the barium follow through.

(2) What is the differential diagnosis?

(3) What is the diagnosis?

Postgrad Med J 2002;78:303

\section{Authors' affiliations}

V A Shenoy, M P N Lewis, Department of General Surgery, Norfolk and Norwich University Hospital NHS Trust, UK

P Preston, Department of Radiology
Correspondence to: Mr V A Shenoy,

Department of Radiology, Norfolk and Norwich University Hospital NHS Trust, Colney Lane,

Norwich NR4 7UZ, UK:

vinodshenoy@hotmail.com

Submitted 9 July 2001

Accepted 19 October 2001

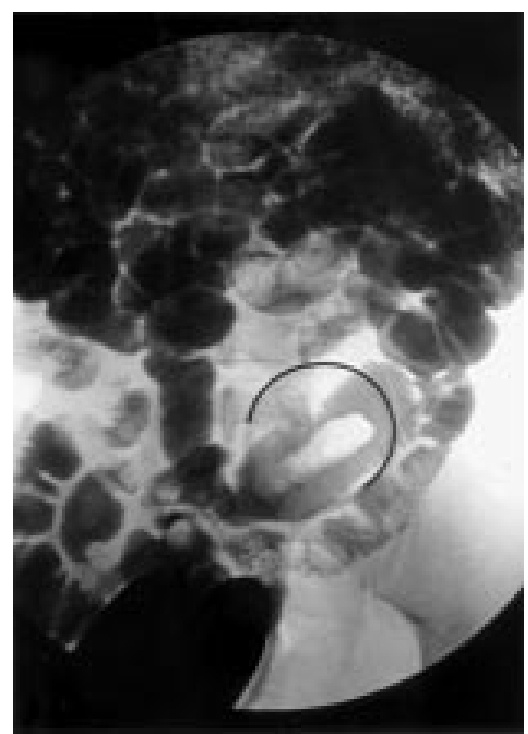

Figure 1 Barium follow through. 